\title{
Hydraulic Fracture Propagation and Permeability Evolution in the Composite Thin Coal Seam
}

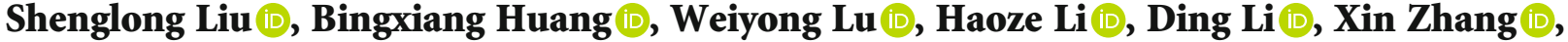 \\ and Binghong $\mathrm{Li}$
}

State Key Laboratory of Coal Resources and Safe Mining, China University of Mining and Technology, Xuzhou 221116, China

Correspondence should be addressed to Bingxiang Huang; huangbingxiang@cumt.edu.cn

Received 26 January 2021; Accepted 9 May 2021; Published 24 May 2021

Academic Editor: Xiang Rao

Copyright (c) 2021 Shenglong Liu et al. This is an open access article distributed under the Creative Commons Attribution License, which permits unrestricted use, distribution, and reproduction in any medium, provided the original work is properly cited.

\begin{abstract}
Hydraulic fracturing can improve the permeability of composite thin coal seam. Recently, characterizing hydraulic fracture (HF) propagation inside the coal seam and evaluating the permeability enhancement with HF extension remain challenging and crucial. In this work, based on the geological characteristics of the coal seam in a coal mine of the southwest China, the RFPA $^{2 \mathrm{D}}$-Flow software is employed to simulate the HF propagation and its permeability-increasing effect in the composite thin coal seam, and a couple of outcomes were obtained. (1) Continuous propagation of the hydraulic microcrack-band is the prominent characteristic of HF propagation. With the increment of the injection-water pressure, HF generation in the composite thin coal seam can be divided into three stages: stress accumulation, stable fracture propagation, and unstable fracture propagation. (2) The hydraulic microcrack-band propagates continuously driven by the fluid-injection pressure. The microcrack-band not only cracks the coal seam but also fractures the gangue sandwiched between the coal seams. (3) The permeability in the composite thin coal seam increases significantly with the propagation of hydraulic microcrack-band. The permeability increases by 1 2 magnitudes after hydraulic fracturing. This study provides references to the field applications of hydraulic fracturing in the composite thin coal seam, such as optimizing hydraulic fracturing parameters, improving gas drainage, and safe-efficient mining.
\end{abstract}

\section{Introduction}

The composite thin coal seam consisting of the layers of coal and gangue is widely distributed in southwest China. To improve the gas-extraction efficiency and control gas-outburst, the permeability of composite thin coal seam needs to be enhanced. To date, hydraulic fracturing, fracturing the rock with high-pressure water, is widely used to improve the poor permeability of composite thin coal seam [1-4]. Therefore, understanding of hydraulic fracture (HF) propagation and permeability evolution in the composite thin coal seam is fundamental to stimulate the composite thin coal seam.

The previous investigations show HF propagation across the layers usually occurs in the height direction $[5,6]$. The HF propagation law depends on many factors, such as the in situ stresses (confining pressures), rock properties, the distribution of weak plane ahead of the fracture extension path, and fluid-injection parameters. More specially, the weak hor- izontal plane distributing ahead of the fracture tip significantly reduces the HF height [6]. The HF geometries are determined by the in situ stress difference between production layer and interlayer [7-9], elastic parameter difference [10-12], fracture toughness difference [13-15], interface strength [15], the distribution of fluid-injection pressure inside the fracture, and rheological and viscous characteristics of fracturing fluid [16-19].

Understanding the HF propagation rule is crucial to better control HF propagation in the composite thin coal seam. The recent investigations focus on the final HF geometries; however, characterizing HF propagation remains challenging. Due to the massive natural weak planes (crack, cleat, bedding, etc.) and layer structures inside the rock materials, the composite thin coal seam presents remarkably heterogeneous and discontinuous characteristics [20-22]. Besides, the generation of microcrack zone ahead of the fracture tip is the prominent fracturing characteristic of rock-like materials 
[23-26], and the seepage characteristics of injection-fluid in the HF microcrack-band aggravate the complexity of HF propagation $[27,28]$. Therefore, the traditional hydraulic fracturing models are supposed to be insufficient to delineate HF extension and permeability evolution in the composite thin coal seam. In recent years, the software of Rock Failure Process Analysis (RFPA) has been widely used to fluidsolid coupling simulation of porous materials, such as rocklike materials $[29,30]$. In RFPA, the damage mechanics model between elements can be applied to simulate the microcrack zone development surrounding HF, i.e., the real fracturing characteristics of HF extension; further, the permeability evolution with HF propagation in the thin coal seam can be better delineated.

In this work, based on the geological characteristics of a composite thin coal seam in a coal mine in southwest China, the HF propagation in the composite thin coal seam was characterized with RFPA $^{2 \mathrm{D}}$-Flow simulation. Then, the HF propagation law considering microcrack-band development and the permeability evolution with HF extension were analyzed and determined, based on the simulation results. The research results can guide the field construction of hydraulic fracturing in the mining process of coal seam with multilayer gangue in southwest China and even around the world and provide new ideas and methods for the study of fracture propagation rule through the bedding plane.

\section{Geological Conditions of the Composite Thin Coal Seam}

In this work, we simulated the HF propagation in the composite thin coal seam of $\mathrm{K}_{7}$ (Figure 1), located in a coal mine of southwest China. $K_{7}$ coal seam (depth: $+160 \mathrm{~m}$; thickness: $0.8 \sim 1.2 \mathrm{~m}$ ) is approximate horizontal distributed, with a slight dip angle of $1^{\circ} \sim 3^{\circ}$. The composite thin coal seam, $K_{7}$, involves six layers of coal and gangue as in Figure 1. The multilayers in the composite thin coal seam increase the complexity of HF propagation and permeability, which will be discussed with numerical simulation in the next context.

\section{Damage Mechanics Model of Fluid- Solid Coupling}

3.1. Basic Assumptions. The RFPA ${ }^{2 \mathrm{D}}$-Flow was employed to simulate HF propagation in the composite thin coal seam of $\mathrm{K}_{7}$, following four basic assumptions [29]:

(1) The fluid in the rock material medium follows Biot seepage theory. (2) The rock materials are brittle and elastic, with residual strength. Besides, the mechanical behaviour of rock during loading and unloading obeys the elastic damage theory. (3) The element damage threshold follows two criteria, i.e., the maximum tensile strength criterion and Mohr-Coulomb criterion. (4) In the elastic stress state, the material is elastic and brittle. (5) The relationship between stress and permeability coefficient obeys the negative exponential relation, and the permeability coefficient increases obviously after material failure. (5) The mechanical properties assigned to all elements obey Weibull distribution, to simulate material heterogeneity

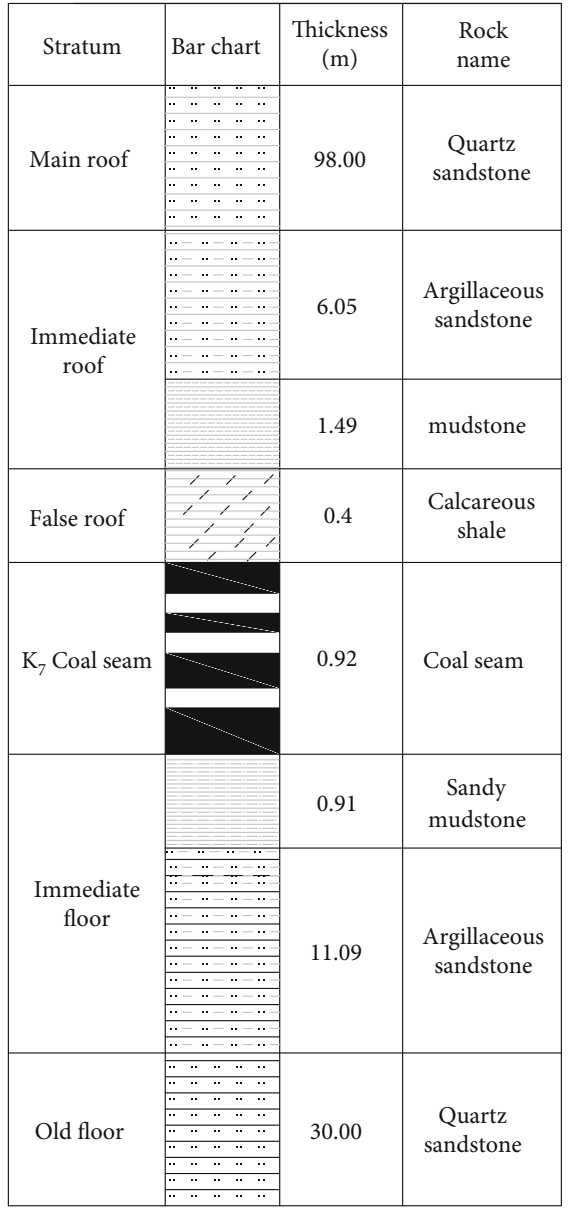

FIgURE 1: Geology drill-columnar section.

3.2. Coupling Equation of Seepage-Stress. Hydraulic fracturing is a typical fluid-solid coupling behaviour. The fluidsolid coupling equations utilized in RFPA $^{2 \mathrm{D}}$-Flow simulation mainly involve equilibrium equation, geometric equation, constitutive equation, seepage equation, and governing equation [31], as shown in Eq. (1).

$$
\begin{cases}\frac{\partial \sigma_{i j}}{\partial X_{i}}+\rho X_{i}=0 \text { equilibrium equation, } & \\ \varepsilon_{i j}=\frac{1}{2}\left(u_{i, j}+u_{j, i}\right) & \text { geometric equation, } \\ \sigma_{i j}^{\prime}=\sigma_{i j}-\alpha P \delta_{i j}=\lambda \delta_{i j}+2 G \varepsilon_{i j} & \text { constitutive equation, } \\ k \nabla^{2} P=\frac{1}{Q} \frac{d P}{d t}-\alpha \frac{\partial \varepsilon_{v}}{\partial t} & \text { seepage equation, } \\ k(\sigma, P)=k_{0} \exp \left[-\beta\left(\frac{\sigma_{i j} / 3-\alpha P}{H}\right)\right] & \text { governing equation, }\end{cases}
$$

where $\sigma_{i j}$ is the stress tensor, $\rho$ the density, $X_{i j}$ the space vector, $\varepsilon_{i j}$ the strain tensor, $u$ the displacement vector, $\sigma_{i j}^{\prime}$ the effective stress tensor, $\alpha$ the coefficient parameter of effective 


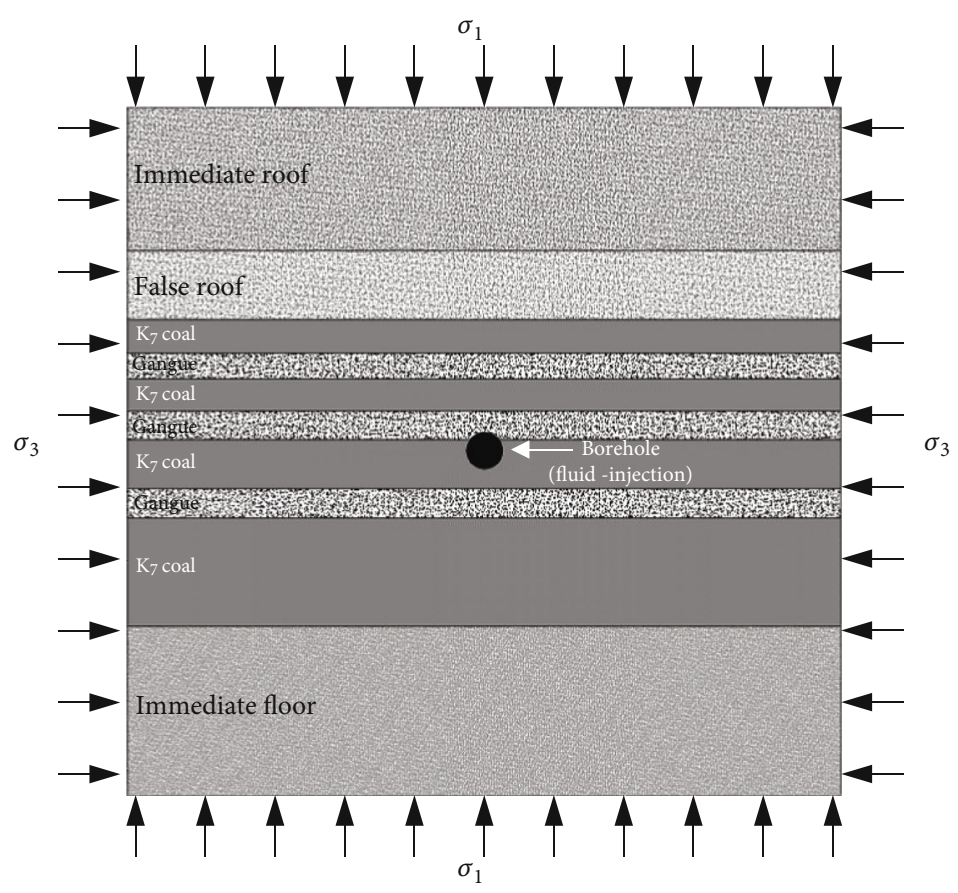

FIGURE 2: The geometry model of hydraulic fracturing with $\mathrm{RFPA}^{2 \mathrm{D}}$-Flow simulation.

TABLE 1: Parameters of RFPA ${ }^{2 \mathrm{D}}$-Flow simulation.

\begin{tabular}{|c|c|c|c|}
\hline Parameters & Values & Parameters & Values \\
\hline Uniaxial compression strength of coal seam & $20 \mathrm{MPa}$ & Horizontal principal stress & $3 \mathrm{MPa}$ \\
\hline Uniaxial compression strength of gangue strata & $35 \mathrm{MPa}$ & Evenness of coal & 1000 \\
\hline Elastic modulus of coal seam & $50000 \mathrm{MPa}$ & Evenness of gangue strata & 1000 \\
\hline Elastic modulus of gangue strata & $70000 \mathrm{MPa}$ & Internal friction angle & $30^{\circ}$ \\
\hline Weight & $1.4 \times 10^{-5} \mathrm{~N} / \mathrm{mm}^{3}$ & Residual strength & $0.1 \%$ \\
\hline Ratio of compression strength to tensile strength & 10 & Coefficient of pore pressure in the coal & 0.1 \\
\hline Initial permeability coefficient of coal & $0.0008 \mathrm{~m} / \mathrm{D}$ & Coefficient of pore water in the gangue & 0.1 \\
\hline Initial permeability coefficient of gangue strata & $0.0006 \mathrm{~m} / \mathrm{D}$ & Maximum compressive strain coefficient & 200 \\
\hline Maximum tensile strain coefficient & 1.5 & Increased injection pressure at each step & $0.2 \mathrm{MPa}$ \\
\hline Initial injection pressure & $3 \mathrm{MPa}$ & Vertical principal stress & $6 \mathrm{MPa}$ \\
\hline
\end{tabular}

stresses, $P$ the pore pressure, $\lambda$ the Lamé constant, $G$ the shear modulus, $k$ the permeability coefficient, $\varepsilon_{\mathrm{v}}$ the volume strain, $k_{0}$ the initial permeability coefficient, and $\beta$ the stress-sensitive parameter.

3.3. Coupled Equation of Seepage-Damage. Once the stress state or strain state of the element attains to the damage threshold value, the element begins to damage. In this work, the weakening elastic modulus is used to delineate element damage, following Eq. (2).

$$
E=(1-D) E_{0}
$$

where $E$ is the elastic modulus of the damaged element, $D$ the damage variable, and $E_{0}$ the initial elastic modulus.
Note that the expressions of the damage variable and permeability coefficient divide into two categories [31], corresponding to the maximum tensile strength criterion and Mohr-Coulomb criterion.

(1) Damage variable and permeability coefficient following Mohr-Coulomb criterion

When the element shear stress reaches the MohrCoulomb damage threshold, the damage variable can be expressed as below.

$$
D= \begin{cases}0 & \varepsilon<\varepsilon_{\mathrm{c} 0}, \\ 1-\frac{f_{\mathrm{cr}}}{E_{0} \varepsilon} & \varepsilon \geq \varepsilon_{\mathrm{c} 0},\end{cases}
$$



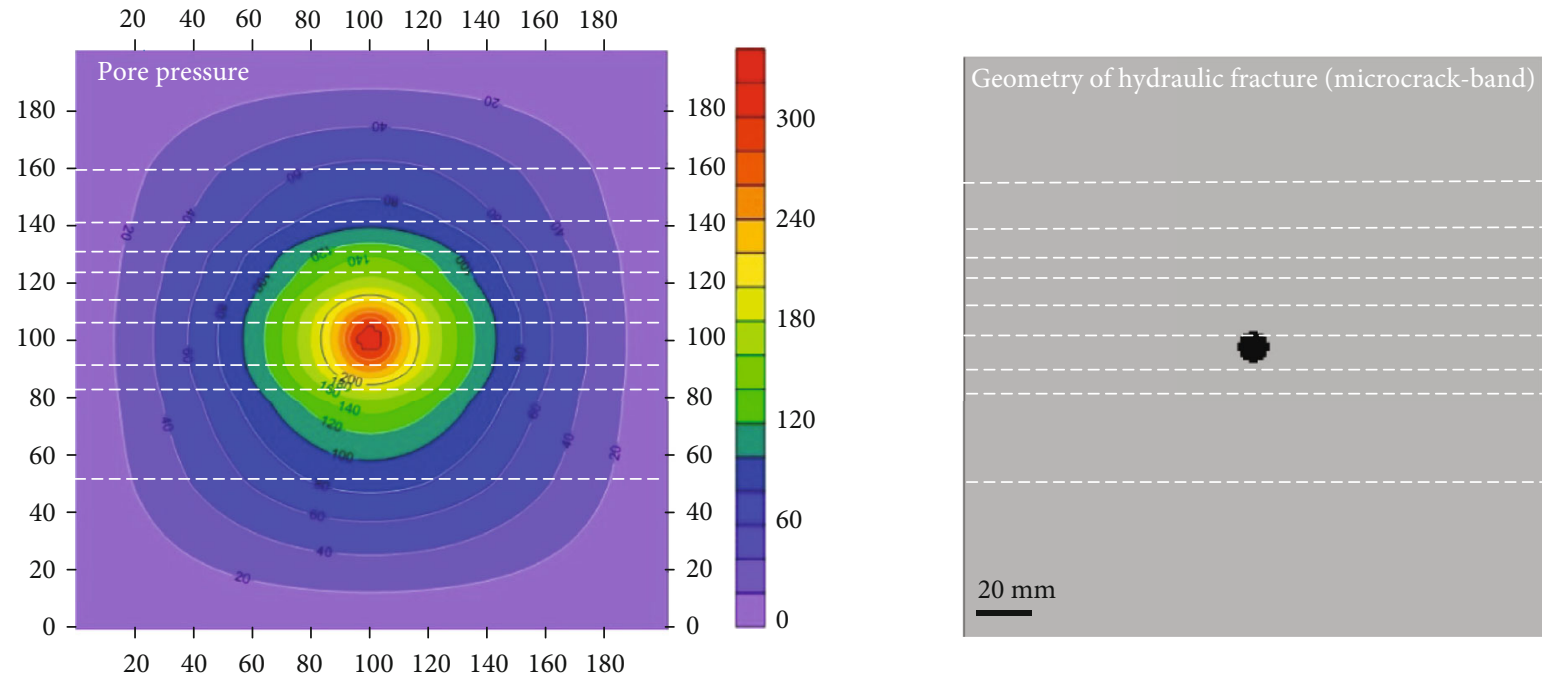

(a) Fluid-injection pressure: $3 \mathrm{MPa}$

$\begin{array}{lllllllll}20 & 40 & 60 & 80 & 100 & 120 & 140 & 160 & 180\end{array}$
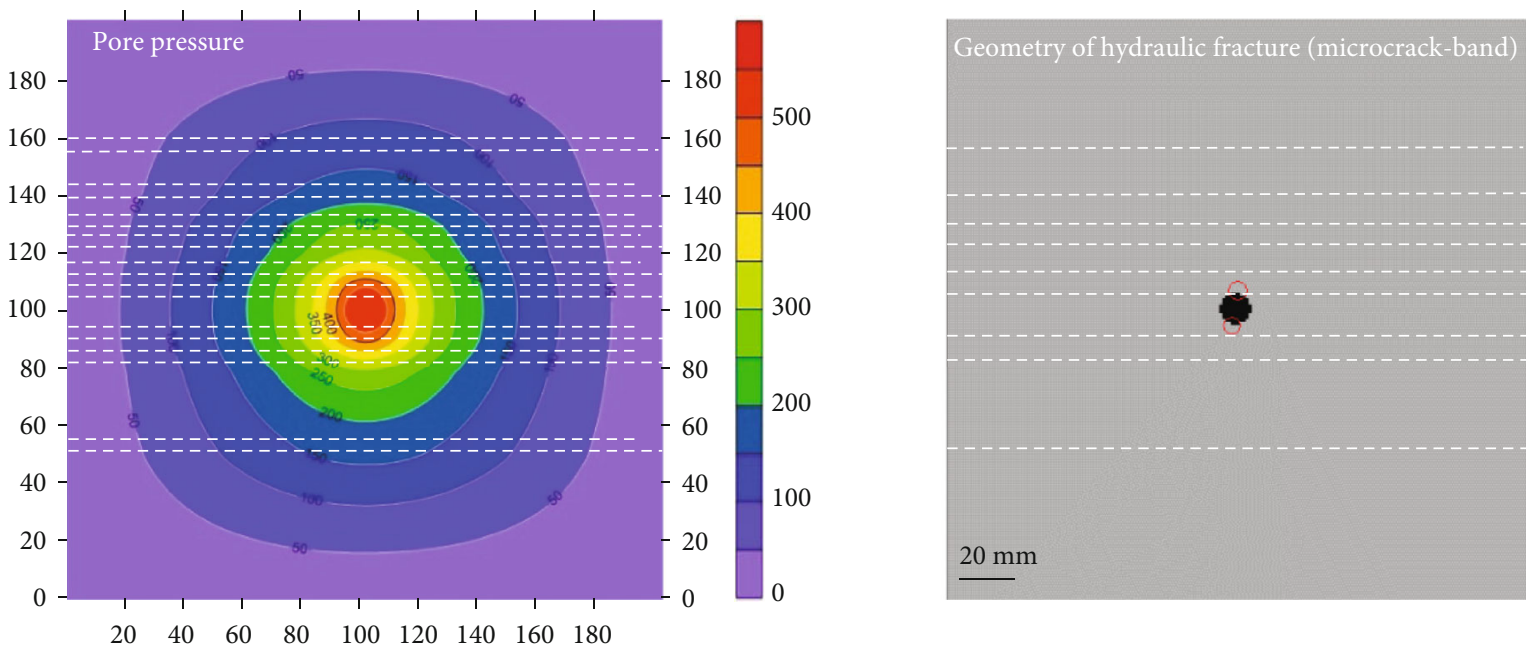

(b) Fluid-injection pressure: $5.4 \mathrm{MPa}$

$\begin{array}{lllllllll}20 & 40 & 60 & 80 & 100 & 120 & 140 & 160 & 180\end{array}$
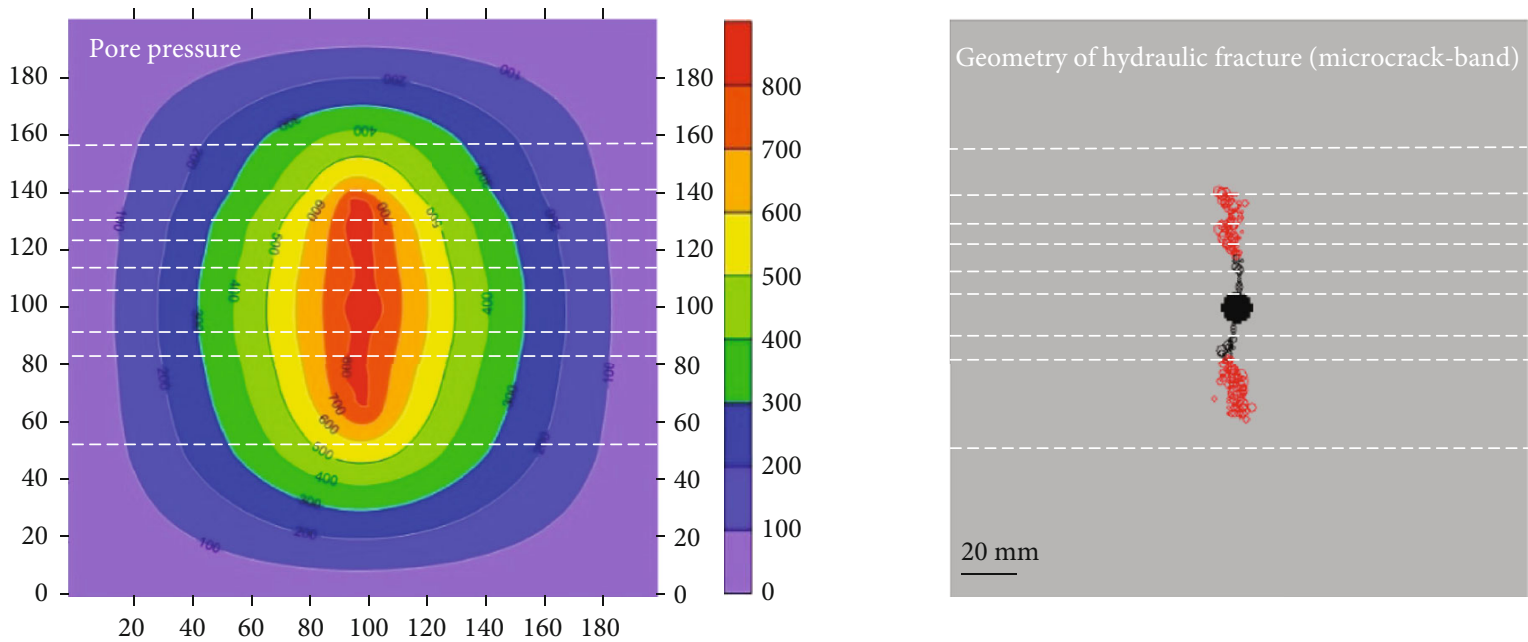

(c) Fluid-injection pressure: $8.2 \mathrm{MPa}$

Figure 3: Continued. 

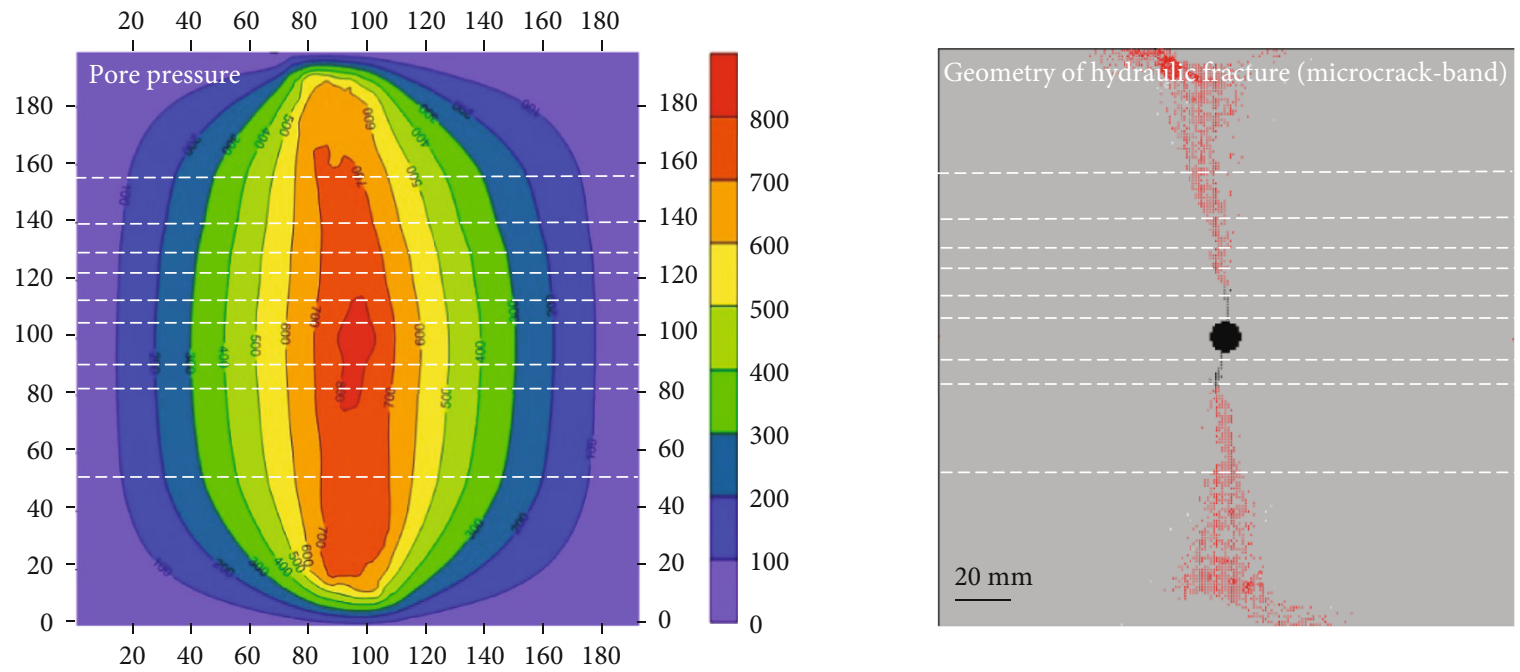

(d) Fluid-injection pressure: $8.2 \mathrm{MPa}$ (continuous injection of fluid)

Figure 3: Pore pressures and hydraulic fracture (microcrack-band) geometries at different injection pressures.

where $\varepsilon_{\mathrm{c} 0}$ is the critical damage strain and $f_{\mathrm{cr}}$ is the critical damage stress. The permeability coefficient of elements is listed below.

$$
k= \begin{cases}k_{0} e^{-\beta\left(\sigma_{1}-\alpha P\right)} & D=0, \\ \xi e^{-\beta\left(\sigma_{1}-\alpha P\right)} & D \leq 0 .\end{cases}
$$

(2) Damage variable and permeability coefficient following maximum tensile strength criterion

The damage threshold and the damage variable $D$ can be expressed in Eqs. (5) and (6), if the element reaches the damage threshold of tensile strength $f_{t}$.

$$
D=\left\{\begin{array}{c}
\sigma_{3} \leq-f_{t}, \\
1-\frac{f_{\mathrm{cr}}}{E_{0} \varepsilon} \quad \begin{array}{c}
\varepsilon<\varepsilon_{\mathrm{tu}} \leq \varepsilon<\varepsilon_{\mathrm{c} 0}, \\
1
\end{array} \quad \varepsilon \geq \varepsilon_{\mathrm{c} 0} .
\end{array}\right.
$$

The permeability coefficient of elements follows.

$$
k= \begin{cases}k_{0} e^{-\beta\left(\sigma_{3}-\alpha P\right)} & D=0, \\ \xi e^{-\beta\left(\sigma_{3}-\alpha P\right)} & 0<D<1, \\ \xi e^{-\beta\left(\sigma_{3}-\alpha P\right)} & D=1 .\end{cases}
$$

Based on the above model, the discrete element method will be used to calculate the coupling seepage-stress, with the coupled iterative solution.

\section{Numerical Simulation Schemes}

The RFPA ${ }^{2 \mathrm{D}}$-Flow simulation scheme of HF propagation in the composite thin coal seam will be represented in this section. The 2D geometrical model is shown in Figure 2, with a dimension of $200 \mathrm{~mm} \times 200 \mathrm{~mm}$. The validity of the numerical model representing the actual fracture process will decrease if the size of the discrete element is too large. The effectiveness of simulation results is mainly depending on whether the fracture process is in accord with the actual. If the geometry size of the established numerical model is the same as that in field application, the element numbers with small size will be extremely large. Then, the calculation efficiency will decrease remarkably (even unable to calculate). In contrast, if choosing large-size elements, the applicability of numerical simulation to real rock fracturing will decrease. Therefore, to better characterize the actual rock fracturing and increase the calculation efficiency of numerical simulation, this geometrical model represents the real composite thin coal seam and is reduced by 0.1 times. As shown in Figure 2, three gangue layers are embedded in the coal seam, corresponding to the real geological characteristics of the $\mathrm{K}_{7}$ coal seam in Figure 1.

The numerical simulation model follows the plane stress condition. The increasing water pressure in the borehole in each step indicates the fluid-injection during hydraulic fracturing. The vertical and horizontal in situ stresses applied to the model boundaries are set as $5 \mathrm{MPa}$ and $3 \mathrm{MPa}$, respectively. The initial boundary pore pressure is 0 . All the parameters in the numerical simulation model are listed in Table 1.

\section{Propagation Process of the Hydraulic Fracture in the Composite Thin Coal Seam}

The fluid-injection pressure in the hole increases from $3 \mathrm{MPa}$ with a rate of $0.2 \mathrm{MPa} / \mathrm{step}$. The pore pressure surrounding the borehole increases with the rising injection pressure. 


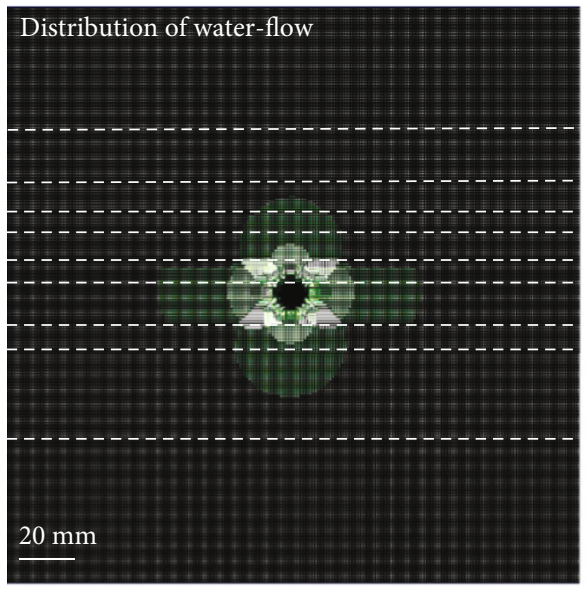

$0.01 E+001$
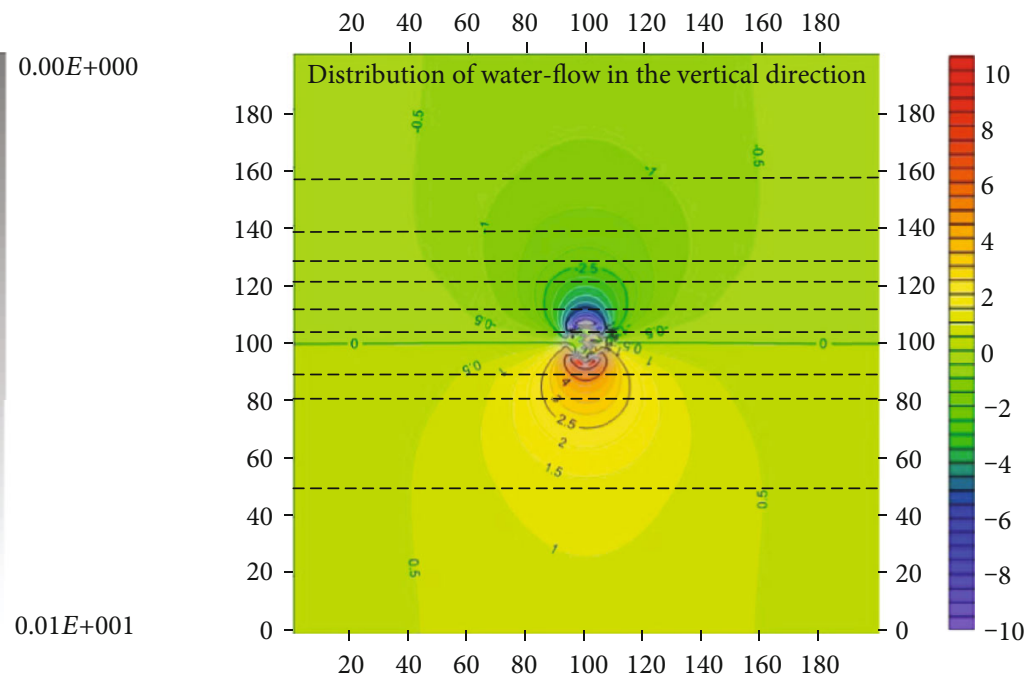

(a) Fluid-injection pressure: $3 \mathrm{MPa}$
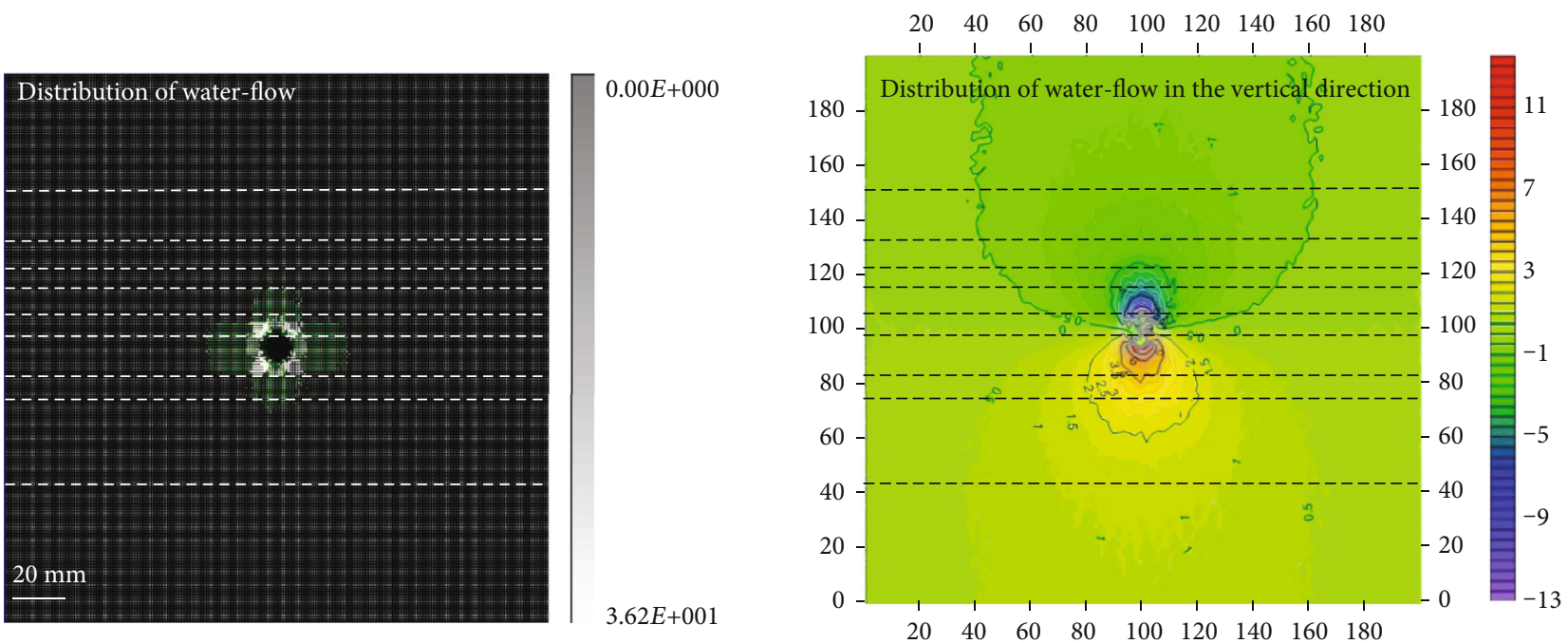

(b) Fluid-injection pressure: $5.4 \mathrm{MPa}$
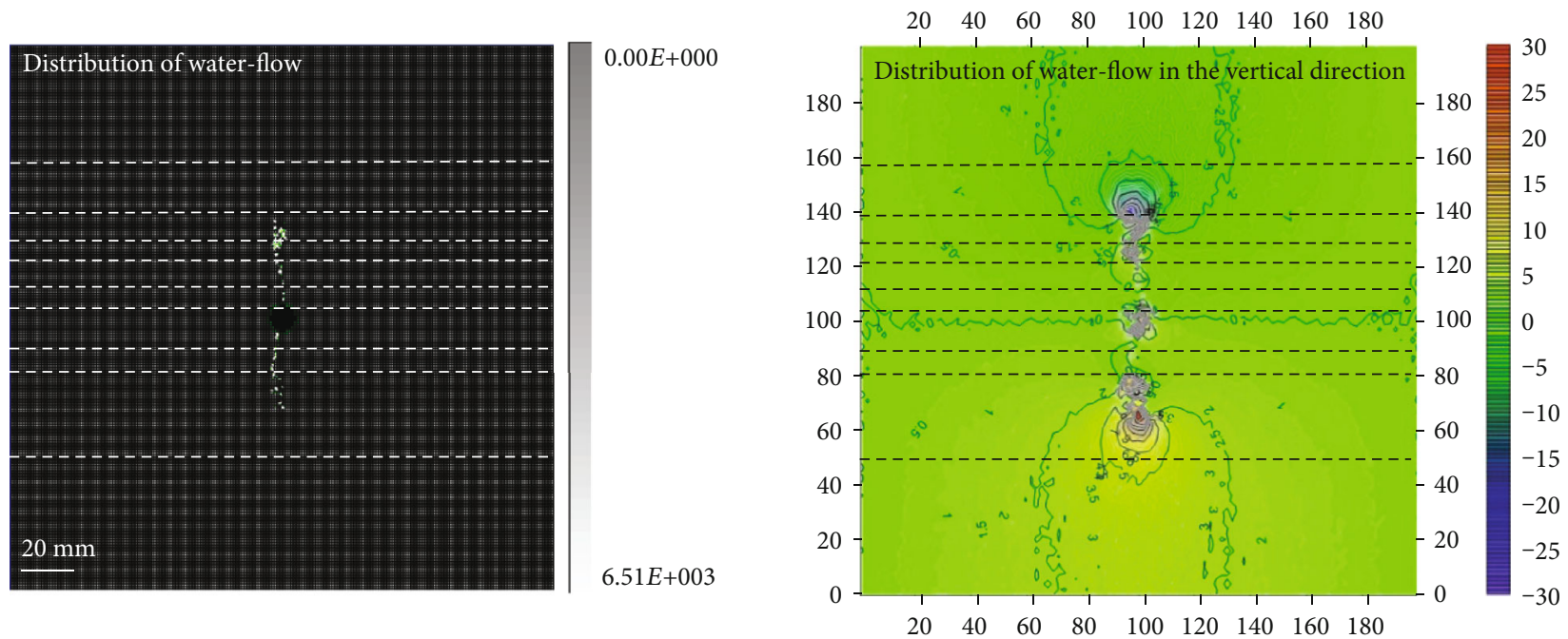

(c) Fluid-injection pressure: $8.2 \mathrm{MPa}$

FIgURe 4: Continued. 

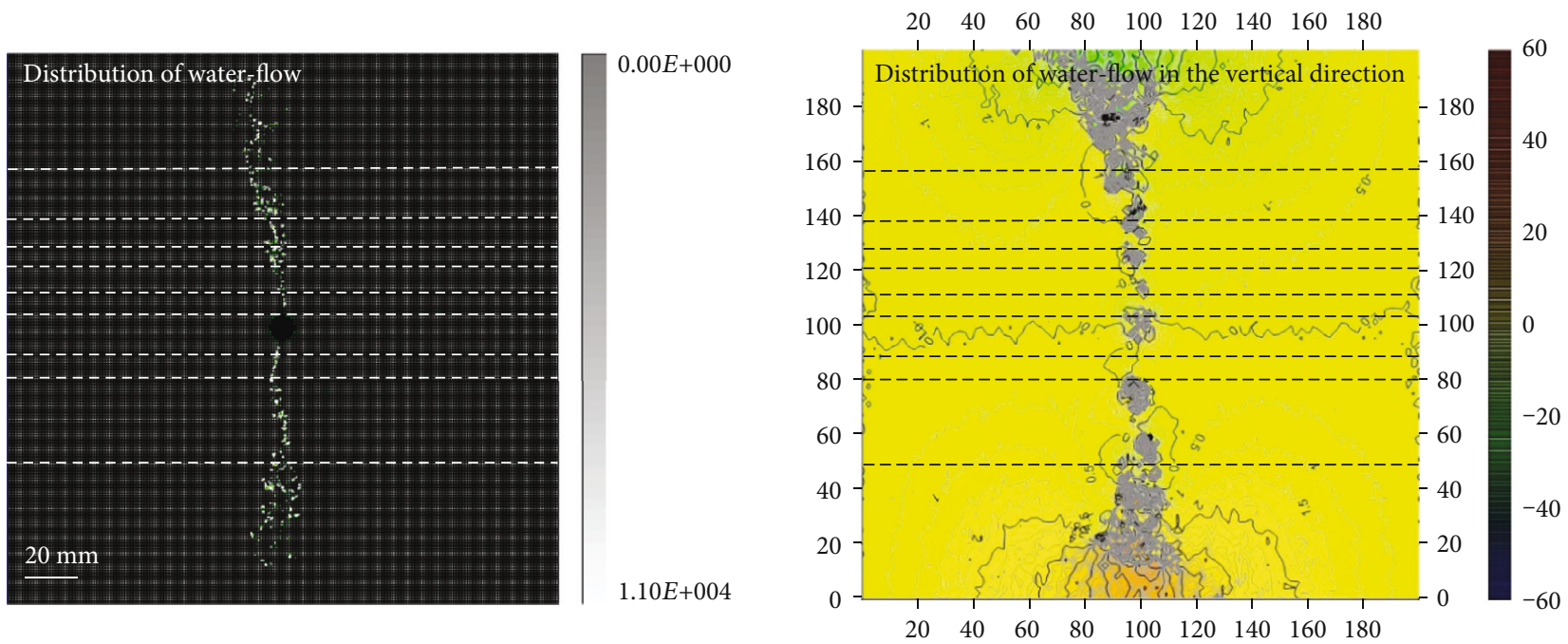

(d) Fluid-injection pressure: $8.2 \mathrm{MPa}$ (continuous injection of fluid)

FIgURE 4: Distributions of water flow and its vertical component.

The hydraulic microcrack-band extends significantly perpendicular to the minimum principal stress. Most investigations show generating microcrack zone (i.e., fracture process zone, FPZ) ahead of the fracture tip is the prominent fracturing characteristic of rock-like materials, which causes the microcrack-band extension with the continuous development of FPZ [16-19]. Along the symmetry-axis of the microcrack bond, the fusion of a large number of microcracks realizes the real hydraulic crack propagation. Therefore, the simulation results of HF propagation are consistent with the actual situation.

Based on Figure 3, HF propagation in the composite thin coal seam can be concluded as four categories. (1) With the continuous injection of fracturing fluid, the injection pressure accumulates continuously and modifies the stress field in the composite thin coal seam. When the injection pressure reaches $3 \mathrm{MPa}$, almost no microcracks generate in coal and rock mass, which indicates that the coal and rock mass have not yet been broken. Besides, the pore pressure concentrates surrounding the borehole (Figure 3(a)). (2) With injection pressure increasing, the concentration of pore pressure surrounding the borehole becomes more remarkable. When the injection pressure reaches $5.4 \mathrm{MPa}$, microcracks start to generate surrounding the borehole and tend to develop along the vertical direction (Figure 3(b)). (3) When the injection pressure increases to $8.2 \mathrm{MPa}$, the microcrackband extends remarkably, which implying HF propagation. The pore pressure presents an elliptical shape due to the extended HF (Figure 3(c)). (4) With the continuous injection of fracturing fluid, though the water-injection pressure is still $8.2 \mathrm{MPa}$, the hydraulic fracture propagates through the composite thin coal seam completely, and the width of microcrack-band increases significantly (Figure 3(d)). Namely, HF propagates unstably. Note that the increased volume of microcrack-band is related to the enhancement of permeability in the composite thin coal seam, which will be discussed in the next context.
The above analyses indicate that HF propagation in the composite thin coal seam presents as the continuous development of hydraulic microcrack-band. In the composite thin coal seam, HF propagation can be divided into three stages, stress accumulation surrounding the borehole (Figure 3(a)), HF stable propagation (Figure 3(b)), and HF unstable propagation (Figures $3(\mathrm{c}$ ) and $3(\mathrm{~d})$ ).

\section{Permeability Evolution Process of Composite Thin Coal Seam}

6.1. Water Flow Distribution during HF Propagation. The water flow property is an index characterizing the permeability during hydraulic fracturing. In this part, the permeability evolution law due to HF propagation will be analyzed. Corresponding to the HF propagation, the water flow and its vertical component are shown in Figure 4. The water flow characteristics during HF propagation can be divided into four stages. (1) When the injection pressure reaches $3 \mathrm{MPa}$, the water flow is remarkable surrounding the borehole and presents symmetrical distribution mode. Given the low injection pressure less than the tensile strength, no cracks generate as in Figures 3(a) and 4(a). (2) With the injection pressure increasing to $5.4 \mathrm{MPa}$, the water flow surrounding the borehole distributes along the vertical direction remarkably, which is supposed to be caused by the generation of microcracks surrounding the borehole (Figure 4(b)). (3) When the injection pressure reaches $8.2 \mathrm{MPa}$, the vertical component of water flow becomes more obvious, due to the stable propagation of hydraulic microcrack-band (Figure 4(c)). In detail, the maximum flow rate in the vertical direction attains to $30 \mathrm{~m}^{2} / \mathrm{d}$, which is increased by 3 times compared to the initial injection state $\left(10 \mathrm{~m}^{2} / \mathrm{d}\right)$ as in Figure $4(\mathrm{a})$. (4) With the continuous water-injection, though the injection pressure is kept at 8.2 $\mathrm{MPa}$, high water flow zone expands more remarkable, due to the continuous extension of the hydraulic microcrack-band (Figure $4(\mathrm{~d})$ ). The maximum flow rate in 


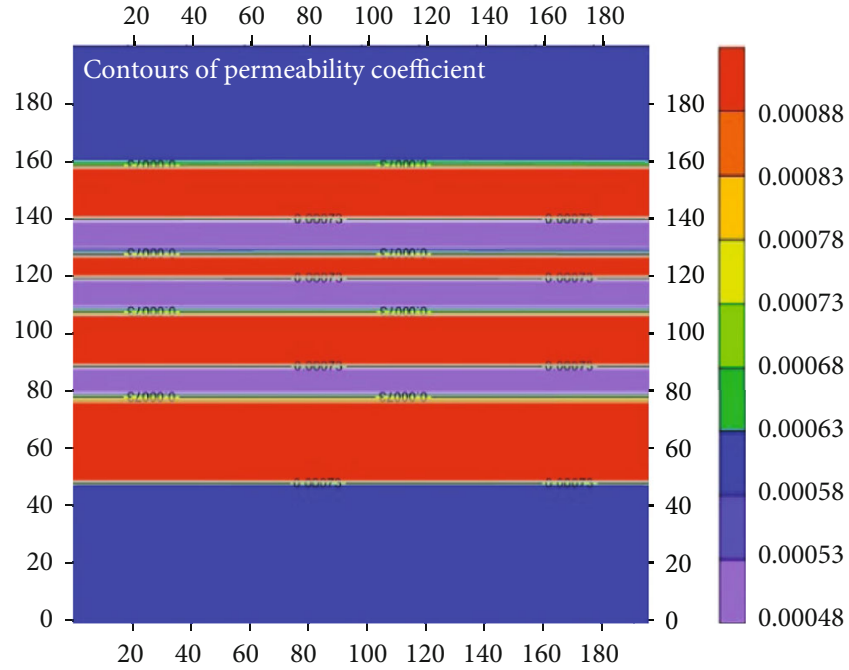

(a) Fluid-injection pressure: $3 \mathrm{MPa}$

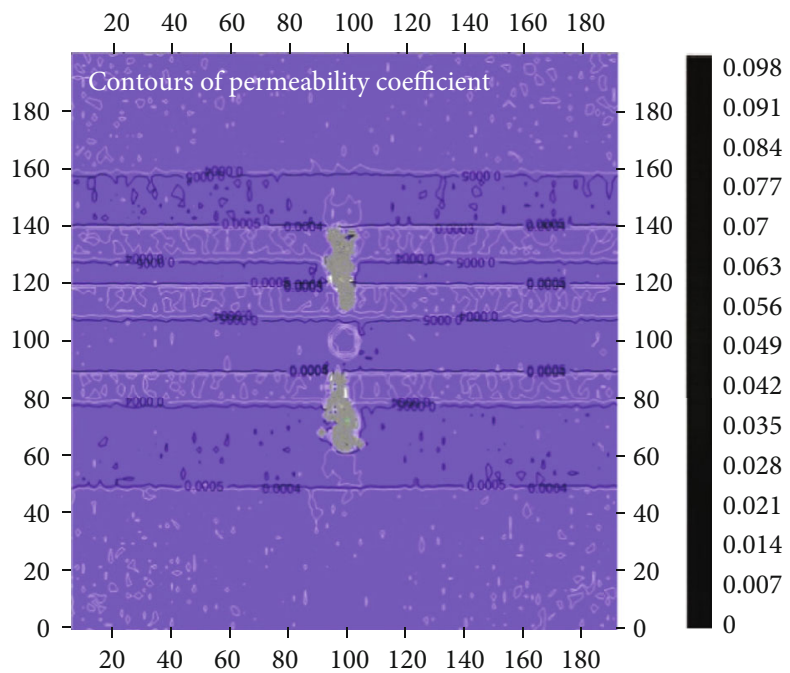

(c) Fluid-injection pressure: $8.2 \mathrm{MPa}$

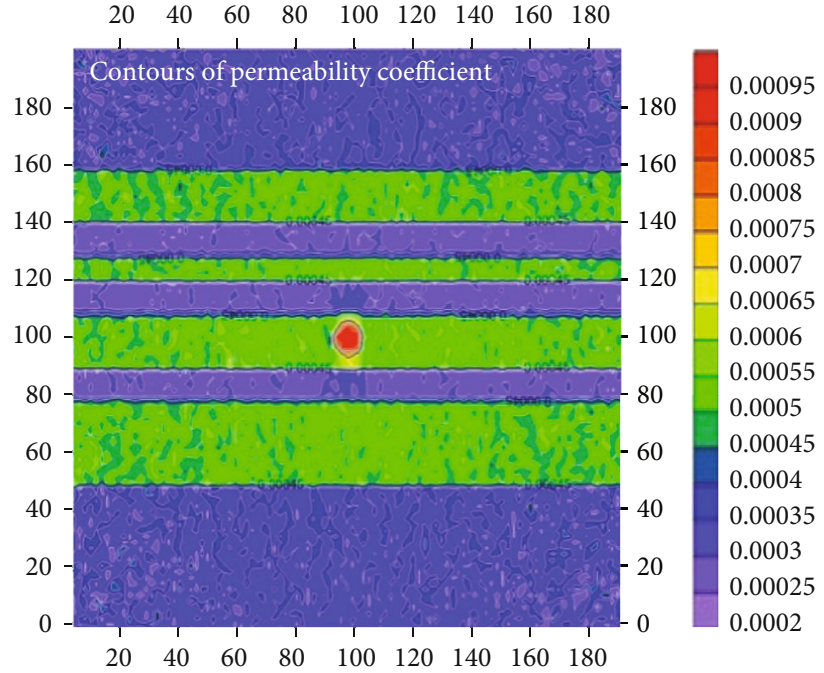

(b) Fluid-injection pressure: $5.4 \mathrm{MPa}$

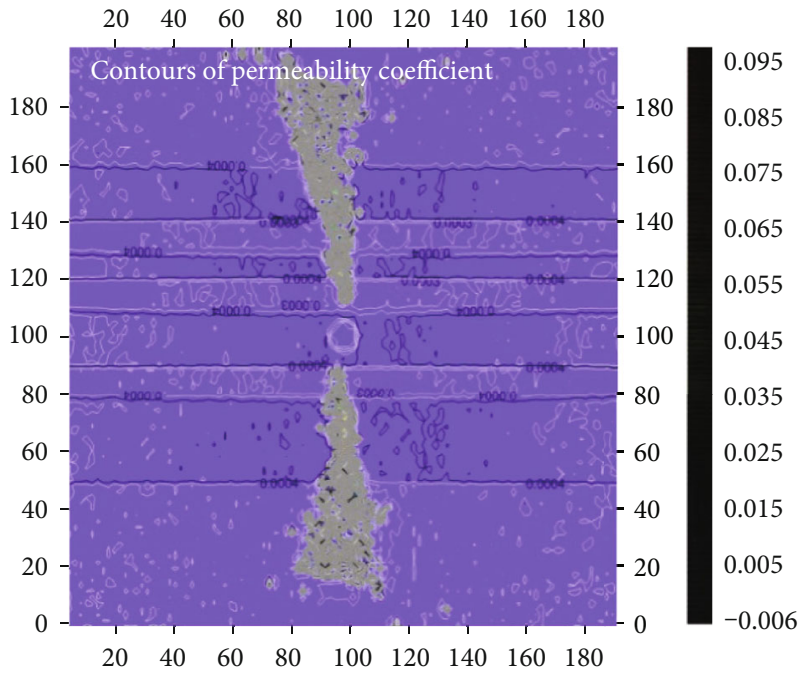

(d) Fluid-injection pressure: $8.2 \mathrm{MPa}$ (continuous injection of fluid)

FIGURE 5: The distribution of permeability coefficient in the vertical direction during hydraulic fracturing.

the vertical direction reaches $60 \mathrm{~m}^{2} / \mathrm{d}, 6$ times that of the initial injection state. The above evolution rule of the water flow is consistent with the propagation of hydraulic microcrackband.

\subsection{Permeability Evolution in the Composite Thin Coal Seam.} In this part, the permeability evolution in the composite thin coal seam during hydraulic fracturing will be analyzed, with the permeability coefficient (Figure 5 ). The permeability evolution includes four stages from Figures 5 and 3. (1) The initial water-injection pressure is $3 \mathrm{MPa}$. Correspondingly, the initial permeability coefficients in the coal seam and gangue are $0.0008 \mathrm{~m} / \mathrm{d}$ and $0.0002 \sim 0.0006 \mathrm{~m} / \mathrm{d}$, respectively (Figure 5(a)). (2) When the injection pressure reaches $5.4 \mathrm{MPa}$, the permeability coefficient surrounding the borehole ranges from $0.00085 \mathrm{~m} / \mathrm{d}$ to $0.00095 \mathrm{~m} / \mathrm{d}$ (Figure 5(b)), which is increased by 1.06 1.2 times. (3) With fluidinjection pressure increasing to $8.2 \mathrm{MPa}$, the maximum permeability coefficient in the coal and gangue reaches
$0.098 \mathrm{~m} / \mathrm{d}$ (Figure 5(c)), which is 122.5 times of the initial state. The significant increment of permeability is due to the extension of hydraulic microcrack-band, and the highpermeability zone is larger than the HF stimulation area, which indicates the dominant seepage path is not along with the HF but also surrounding the HF. Thus, increasing the hydraulic microcrack-band volume is beneficial for enhancing permeability in the composite thin coal seam. (4) With the continuous injection of fracturing fluid, due to the extension of hydraulic microcrack-band, i.e., the hydraulic fracture, the permeability coefficient increases dramatically (Figure $5(\mathrm{~d})$ ), reaching $0.1 \mathrm{~m} / \mathrm{d}$ (125 times of the maximum permeability coefficient of the initial state).

Above all, hydraulic fracturing is fundamental to the permeability enhancement in the composite thin coal seam. More specially, with the continuous propagation of the hydraulic fracture, i.e., the hydraulic microcrack-band, the permeability in the coal seam increases by 1 2 magnitude. This investigation can provide references to field applications of hydraulic 
fracturing in the composite thin coal seam, which is beneficial for optimizing hydraulic fracturing parameters, improving gas drainage and safe-efficient mining.

\section{Discussions}

Nucleation and coalescence of massive microcracks constitute the real fracture process of rock, making the microcrack-band distributes along the real hydraulic fracture surface. However, most previous investigations on the simulations of hydraulic fracturing focus on the macro fracture extension, neglecting the extension of the microcrack-band. In this work, the discrete element method (DEM) is employed to simulate the microcrack-band extension in the coal-gangue interbedded (four coal and three gangues) rock, with the advantage of DEM suitable for simulating the onsets of microcrack in rock. Therefore, the fracturing simulation method utilized in this work is more in accord with the physical process of hydraulic fracturing. This study not only characterizes the microcrack-band extension but also delineates the permeability evolution due to microcrack-band development. The characterization for fracture propagation and permeability evolution in the coal-gangue interbedded (four coal and three gangues) rock can provide theoretical references for field applications.

However, this work also involves some limitations. For instance, (1) the interface is characterized by the bond between two elements simply, but the actual constitutive relation of the interface is more complex. (2) Since monitoring hydraulic fracture propagation in field applications remains challenging, the application of fracturing numerical simulations in this work to the real fracture extension process in the mine needs further validations.

\section{Conclusions}

(1) Generating hydraulic microcrack-band is a prominent characteristic of $\mathrm{HF}$ extension. With rising injection-water pressure, HF propagation in the composite thin coal seam involves three stages: stress accumulation, stable fracture propagation, and unstable fracture propagation

(2) Driven by the fluid-injection pressure, the hydraulic microcrack-band propagates continuously, fracturing both the coal seam and the gangue sandwiched between the coal seam

(3) The permeability of the composite thin coal seam enhances significantly, which is consistent with the propagation of hydraulic microcrack-band. The permeability increases by 1 2 magnitudes after hydraulic fracturing

(4) This study provides theoretical bases for the field applications of hydraulic fracturing in the composite thin coal seam, such as optimizing hydraulic fracturing parameters, improving gas drainage, and safeefficient mining

\section{Nomenclature}

HF: Hydraulic fracture

FPZ: Fracture process zone

$\sigma_{i j}: \quad$ Stress tensor, $\mathrm{MPa}$

$\rho: \quad$ Density, $\mathrm{kg} / \mathrm{m}^{3}$

$X_{i j}$ : Space vector, dimensionless

$u$ : $\quad$ Displacement vector, $\mathrm{m}$

$\varepsilon_{i j}: \quad$ Strain tensor, dimensionless

$\sigma_{i j}^{\prime}: \quad$ Affective stress tensor, $\mathrm{MPa}$

$\alpha$ : The coefficient parameter of effective stresses, dimensionless

$\lambda$ : Lamé constant, dimensionless

$G$ : $\quad$ Shear modulus, GPa

$\varepsilon_{\mathrm{v}}: \quad$ Volume strain, dimensionless

$k$ : $\quad$ Permeability coefficient, $\mathrm{m} / \mathrm{d}$

$k_{0}$ : The initial permeability coefficient, $\mathrm{m} / \mathrm{d}$

$\beta$ : $\quad$ The stress-sensitive parameter, dimensionless

$E$ : The elastic modulus of the damaged element, GPa

$D$ : Damage variable, dimensionless

$E_{0}: \quad$ Initial elastic modulus, GPa

$\varepsilon_{\mathrm{c} 0}$ : Critical damage strain, dimensionless

$f_{\mathrm{cr}}$ : Critical damage stress, MPa.

\section{Data Availability}

All the data have been included in the manuscript.

\section{Conflicts of Interest}

No potential conflict of interest was reported by the authors.

\section{Acknowledgments}

This work was financially supported by the National Science Foundations of China (No. 51774272) and Research Funds for Leading Talents in Science and Technology Innovation of National Ten Thousand Plan (2019-563).

\section{References}

[1] Z. X. Zhang, H. T. Wang, and B. Z. Deng, "Field investigation of hydraulic fracturing in coal seams and its enhancement for methane extraction in the Southeast Sichuan Basin, China," Energies, vol. 11, no. 12, p. 3451, 2018.

[2] Y. W. Li, S. Yang, and W. C. Zhao, "Experimental of hydraulic fracture propagation using fixed-point multistage fracturing in a vertical well in tight sandstone reservoir," Journal of Petroleum Science and Engineering, vol. 171, pp. 704-713, 2018.

[3] B. Hou, R. X. Zhang, and Y. J. Zeng, "Analysis of hydraulic fracture initiation and propagation in deep shale formation with high horizontal stress difference," Journal of Petroleum Science and Engineering, vol. 170, pp. 23-243, 2018.

[4] C. R. Clarkson, S. M. Ghaderi, and M. S. Kanfar, "Estimation of fracture height growth in layered tight/shale gas reservoirs using flowback gas rates and compositions-part II: field application in a liquid-rich tight reservoir," Journal of Natural Gas Science and Engineering, vol. 36, pp. 1031-1049, 2016. 
[5] J. Xie, "A 3-D hydraulic fracture propagation model applied for shale gas reservoirs with multiple bedding planes," Engineering Fracture Mechanics, vol. 228, p. 106872, 2020.

[6] P. Xing, "Laboratory demonstration of hydraulic fracture height growth across weak discontinuities," Geophysics, vol. 83, no. 2, pp. MR93-MR105, 2018.

[7] N. R. Warpinski, R. A. Schmidt, and D. A. Northrop, "In-situ stresses: the predominant influence on hydraulic fracture containment," Journal of Petroleum Technology, vol. 34, no. 34, pp. 653-664, 1998.

[8] P. Xing, A. P. Bunger, and K. Yoshioka, "Experimental study of hydraulic fracture containment in layered reservoirs," in 50th US Rock Mechanics/Geomechanics Symposium, Houston, Texas, 2016, ARMA-2016-049.

[9] J. D. Bredehoeft, R. G. Wolff, and W. S. Keys, "Hydraulic fracturing to determine the regional in situ stress field, Piceance Basin, Colorado," Geological Society of America Bulletin, vol. 87, no. 2, p. 250, 1976.

[10] L. W. Teufel and J. A. Claek, "Hydraulic fracture propagation in layered rock: experimental studies of fracture containment," Society of Petroleum Engineers Journal, vol. 24, no. 1, pp. 1932, 1984

[11] D. B. Van Dam, P. Papanastasiou, and C. J. De Pater, "Impact of rock plasticity on hydraulic fracture propagation and closure," Spe Production \& Facilities, vol. 17, no. 3, pp. 149-159, 2000.

[12] H. A. M. Van Ewkelen, "Hydraulic fracture geometry: fracture containment in layered formations," Society of Petroleum Engineers Journal, vol. 22, no. 3, pp. 341-349, 1982.

[13] H. Gu and X. Weng, "Criterion for fractures crossing frictional interfaces at non-orthogonal angles," in The 44th US rock mechanics symposium and the 5th US-Canada Rock Mechanics Symposium, Salt Lake City, 2010, ARMA-10-198.

[14] M. Sarmadivaleh and V. Rasouli, "Modified Reinshaw and Pollard criteria for a non-orthogonal cohesive natural interface intersected by an induced fracture," Rock Mechanics and Rock Engineering, vol. 47, no. 6, pp. 2107-2115, 2014.

[15] T. G. Fan and G. Q. Zhang, "Laboratory investigation of hydraulic fracture networks in formations with continuous orthogonal fractures," Energy, vol. 74, no. 2, pp. 164-173, 2014.

[16] E. M. Llanos, R. G. Jwffrey, and R. Hillis, "Hydraulic fracture propagation through an orthogonal discontinuity: a laboratory, analytical and numerical study," Rock Mechanics and Rock Engineering, vol. 50, no. 8, pp. 1-18, 2017.

[17] Z. L. Zhou, G. Q. Zhang, and H. R. Dong, "Creating a network of hydraulic fractures by cyclic pumping," International Journal of Rock Mechanics and Mining Sciences, vol. 97, no. 1, pp. 52-63, 2017.

[18] M. A. Biot, W. L. Medlin, and L. Masse, "Fracture penetration through an interface," Society of Petroleum Engineers Journal, vol. 23, no. 6, pp. 857-869, 1983.

[19] B. C. Haimson, "FH Cornet, ISRM suggested methods for rock stress estimation-part 3: hydraulic fracturing (HF) and/or hydraulic testing of pre-existing fractures (HTPF)," International Journal of Rock Mechanics and Mining Sciences, vol. 40, no. 7-8, pp. 1011-1020, 2003.

[20] R. Stephen, "A look into what fractures really look like," Journal of Petroleum Technology, vol. 70, no. 11, pp. 28-36, 2018.

[21] Z. Chen, Finite Element Simulation of a Hydraulic Fracture Interacting with a Natural Fracture, Society of Petroleum Engineers, Brisbane, QLD, Australia, 2015.
[22] M. J. AlTammar and M. M. Sharma, Effect of geological layer properties on hydraulic fracture initiation and propagation: an experimental study, Society of Petroleum Engineers, The Woodlands, TX, United states, 2017.

[23] K. Otsuka and H. Date, "Fracture process zone in concrete tension specimen," Engineering Fracture Mechanics, vol. 65, no. 2, pp. 111-131, 2000.

[24] G. I. Barenblatt, “The formation of equilibrium cracks during brittle fracture. General ideas and hypotheses. Axiallysymmetric cracks," Journal of Applied Mathematics and Mechanics, vol. 23, no. 3, pp. 622-636, 1959.

[25] D. S. Dugdale, "Yielding of steel sheets containing slits," Journal of the Mechanics and Physics of Solids, vol. 8, no. 2, pp. 100-104, 1960.

[26] Q. Lin and J. F. Labuz, "Fracture of sandstone characterized by digital image correlation," International Journal of Rock Mechanics and Mining Sciences, vol. 60, pp. 235-245, 2013.

[27] Y. Xing, G. Zhang, and T. Luo, "Hydraulic fracturing in hightemperature granite characterized by acoustic emission," Journal of Petroleum Science and Engineering, vol. 178, pp. 475484, 2019.

[28] Y. Wu, L. Cheng, L. Ma et al., "Transient two-phase flow model for production prediction of tight gas wells with fracturing fluid-induced formation damage," Journal of Petroleum Science and Engineering, vol. 199, article 108351, 2021.

[29] W. Y. Lu, Y. L. Wang, and X. Zhang, "Numerical simulation on the basic rules of multihole linear codirectional hydraulic fracturing," Geofluids, vol. 14, 2020.

[30] L. C. Li, T. H. Yang, Z. Z. Liang, W. C. Zhu, and C. Tang, "Numerical investigation of groundwater outbursts near faults in underground coal mines," International Journal of Coal Geology, vol. 85, no. 3-4, pp. 276-288, 2011.

[31] F. Z. Yan, B. Q. Lin, C. J. Zhu et al., "A novel ECBM extraction technology based on the integration of hydraulic slotting and hydraulic fracturing," Journal of Natural Gas Science and Engineering, vol. 22, pp. 571-579, 2015. 